\title{
The Impact of Retrofitting Work on Awareness Raising and Knowledge Transfer in Aceh Province, Indonesia
}

\author{
Hari Darshan Shrestha ${ }^{1, *}$, Jishnu Subedi ${ }^{1}$, Ryuichi Yatabe ${ }^{2}$, and Netra Prakash Bhandary ${ }^{2}$ \\ ${ }^{1}$ Department of Civil Engineering, Institute of Engineering, Tribhuvan University, Pulchowk, Kathmandu, Nepal \\ ${ }^{2}$ Graduate School of Science and Engineering, Ehime University, Matsuyama, Ehime 790-8577, Japan
}

\begin{abstract}
Some of the buildings in Aceh Province, Indonesia constructed after the 2004 earthquake and tsunami disaster were found vulnerable. The vulnerable buildings were retrofitted to make them safer and child friendly. Save the Children, one of the implementing agencies, assumed that the process of retrofitting would attract interest from the communities, raise their earthquake awareness, stimulate earthquake safe construction practices, and contribute to earthquake disaster risk reduction. It was also assumed that the retrofitting process would benefit the communities through knowledge transfer of safer construction practices. To assess the impact on awareness and knowledge transfer of the retrofitting work carried out by Save the Children from 2005 to 2008, a survey was carried out in 2009. A total of 104 people who were directly involved in the retrofitting/rehabilitation process were interviewed. The survey covered four districts in Aceh Province, Indonesia where schools, health facilities, and houses were retrofitted. The survey results show that the respondents felt that the impact of retrofitting work on transferring knowledge in the communities was not significant. However, the respondents felt that the retrofitting work had a definite impact on raising awareness of disaster risks and measures for disaster risk reduction.
\end{abstract}

Keywords Aceh Province, disaster awareness raising, disaster risk reduction, Indonesia, knowledge transfer, retrofitting

\section{Introduction}

The December 2004 Indian Ocean Tsunami affected Aceh Province, Indonesia very severely and caused the loss of more than 200,000 lives. Immediately after the tsunami, many humanitarian and aid agencies were involved in rebuilding the devastated areas and invested in reconstruction and infrastructure development of the region under the coordination of the Aceh and Nias Rehabilitation and Reconstruction Agency, commonly referred to by its Indonesian acronym, BRR. In the process of rebuilding Aceh, many residential houses, schools, and health facilities were constructed by different agencies. As the extent of the damage was unimaginable and the aid

\footnotetext{
* Corresponding author. E-mail: harisunita@gmail.com
}

agencies were under pressure to build thousands of facilities in a limited amount of time, most of the agencies had to work with scarce materials and human resources. Moreover, Aceh was embroiled in an armed conflict for 30 years and social, political, and legal institutions were hardly functional even before the disaster. The tsunami washed away everything and transformed the coastal areas into barren fields, which practically ruled out any effective involvement of the communities in rebuilding the tsunami affected areas.

The aftermath of the 2004 earthquake and tsunami presented an unprecedented situation, in terms of the scale of the destruction and the scale of the aid after the disaster. There were huge constraints - political, organizational, environmental, and logistical — in the field that made the reconstruction effort ineffective. Because of the long-running violent conflict prior to the disaster, Martial Law was in effect restricting expatriate access to the province.

Many organizations had trouble scaling up their activities even with more funding than they had ever had before and were under tremendous pressure to spend the funds quickly (Kennedy et al. 2008). It became clear that the "humanitarian agencies lacked the know-how and expertise to lead a mass building exercise" (Oxfam International 2005, 11). It was difficult for the local governments to finalize a plan for moving forward. In April 2005, the Aceh and Nias Rehabilitation and Reconstruction Agency (BRR) was created by the Indonesian central government. The agency drafted policies and guidelines to create common standards and practices and to implement housing reconstruction projects through direct contracting. One of the major problems with the rebuilding process was demand for masonry houses, which were often preferred as appearing to represent "modernization" and development (Kennedy et al. 2008), although they are neither suited to the climate of Aceh, nor the optimal choice considering the earthquake risk that the region is exposed to. The prevalent practice in the region was construction of timber houses for which the locals had both knowledge and skill. As the technology for masonry buildings was relatively new, the construction activities entailed more training.

Although the problems of quality, priority, and approach regarding construction were in the mainstream discussion of 
development agencies, the agencies were under pressure to meet the immediate needs of hundreds of thousands of people in a short time. The development agencies, both donors and implementing agencies, were under pressure to construct schools, health facilities, and houses in a rush. The result was poor quality buildings, vulnerable to future hazards such as earthquakes and floods. To address this vulnerability, some of the agencies carried out vulnerability assessments of the newly constructed buildings and quantified their vulnerability (Shrestha et al. 2012).

Once the new buildings were found to be vulnerable, some agencies decided to retrofit and restrengthen the newly constructed buildings rather than to demolish them and erect new structures. The house owners and communities, however, demanded that new buildings be constructed because they feared that the retrofitting process would be time-consuming, more costly, and technologically unfeasible. In many instances this view was shared by the development agencies. Retrofitting of buildings was a relatively new field, even for technical personnel, at that time. One of the concerns about retrofitting was the cost-effectiveness of the technology. A study carried out after the completion of the retrofitting work implemented by Save the Children revealed that retrofitting is very costeffective if carried out with proper measures (Shrestha et al. 2012). The study justified, albeit in hindsight, the effectiveness of retrofitting from the financial point of view. The difficult aspect of technological feasibility was overcome in the project by adopting local technology, local resources, and local artisans.

The retrofitting work was conceptualized as an initiative with full community participation and local-level engagement for awareness raising and knowledge transfer. One of the five priorities of the Hyogo Framework for Action 20052015 (HFA), a commitment signed by 168 countries in 2005 to build resilience of nations and communities by 2015 , is the "use of knowledge, innovation, and education to reduce underlying risks" (UNISDR 2005, 9). The Hyogo Framework for Action also underscores community participation and technology transfer as two cross-cutting issues for disaster risk reduction. Pearce (2003) suggests that for successful implementation of mitigative strategies, the disaster management process must incorporate community participation from the local decision-making level.

Although community participation is vital, attracting community interest and sustaining that interest is challenging (Karanci and Aksit 2000). Furthermore, participation in community based disaster preparedness may not be effective in raising awareness to the extent of reducing vulnerability, as receiving information does not ensure that the information is used for making decisions that effectively reduce vulnerability (Subedi 2010). The participation of users in up-front decision-making leads to positive results in terms of building processes and outcomes but "despite often-good intentions, this level of participation is rarely obtained and the capabilities of the users are often significantly wasted" (Davidson et al. 2007, 100).
Many factors affect the effectiveness of community participation programs. After comparing disaster preparedness of participants attending a disaster training program with that of people who had not attended the program, Karanci, Aksit, and Dirik (2005) argue that male community members with a higher level of education and smaller household size who are concerned about future disasters and participated in a disaster awareness program contributed to disaster preparedness behaviors. Allen (2006) warns that community based disaster preparedness (CBDP) initiatives have the potential both to empower and disempower, and warns against treating CBDP as a panacea to disaster management problems. There is a danger that community-based initiatives may place greater responsibility on the shoulders of local people without necessarily proportionately increasing their capacity to formulate initiatives according to community understandings and priorities.

The retrofitting work of Save the Children was carried out to reduce the vulnerability of the structures and with the assumption by the decision makers that the process of retrofitting would raise interest from the communities and attract their participation. Participation was assumed to have an impact on the communities by promoting knowledge of safer construction and raising awareness of disaster risks. This article presents a field study of perception of people on impact of the retrofitting works on knowledge of safe construction practices and awareness of disaster risks and measures for disaster risk reduction after the retrofitting work. The field study covers retrofitting of schools as part of the retrofitting projects that included many public facilities such as schools and hospitals and private residential houses in Aceh, carried out by Save the Children from 2005 to 2008.

\section{Retrofitting Work in Aceh}

The location of the retrofitting projects carried out by Save the Children on school buildings, health facilities, and houses in the study area is shown in Figure 1. The study area includes Pidie, Pidie Jaya, Bireuen, and Aceh Utara Districts of Aceh Province, Indonesia. Schools were selected for the study purpose because the work on schools involved the participation of a cross-section of people such as representatives of school management bodies, teachers, and local people from the communities.

\subsection{Damage Assessment}

The 2004 earthquake and the tsunami that followed caused unprecedented losses in the history of Aceh. The scale of damage and loss led, in some cases, to the wiping out of entire communities in parts of Aceh. The summary damage scenario from the assessment carried out by the International Organization for Migration (IOM) in April 2005 is given in Table 1. 


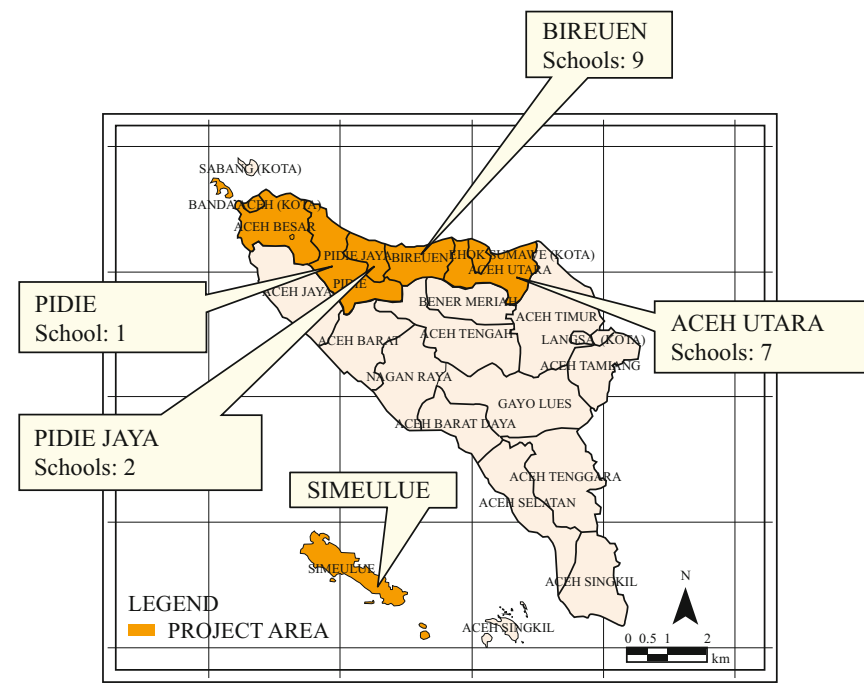

Figure 1. Location of Save the Children retrofitting projects in Aceh Province, Indonesia. In this study only sites with retrofitting of school buildings in Pidie, Pidie Jaya, Bireuen, and Aceh Utara Districts were considered

\subsection{Save the Children's Response}

As part of the relief effort, Save the Children made commitments to support the tsunami affected populations in their efforts to return home. Save the Children's response included providing permanent houses, school buildings, and health facilities and the rehabilitation of existing tsunami affected health facilities. By 2009, Save the Children had built 1,025 homes, 42 schools, 18 health facilities, 4 community learning centers, and 8 early childhood development buildings across 7 districts in Aceh. All housing built/retrofitted incorporated earthquake-resistant design along with all other basic facilities.

Throughout the program implementation, Save the Children was committed to providing safe and child friendly facilities to beneficiaries. Some of the child friendly features included in the design are ramps for disabled children, rounded corners of external walls, doors opening outside with lateral push, non-skid tile on the floor, and hand washing sink with reduced height. However, a later assessment of the newly built facilities revealed that some of them did not meet the expected requirements of disaster safety as proper quality control measures and design provisions were overlooked due to pressure to speed up construction. A decision was made by Save the Children to retrofit the newly constructed vulnerable buildings. The first author of this article was responsible for the overall management of vulnerability assessment, retrofitting and reconstruction program as the Director of the Construction Department, Aceh Tsunami Recovery Program, Save the Children. He was directly involved in the process and monitored the work from vulnerability assessment to implementation of retrofitting projects.

\subsection{The School Retrofitting Process}

Save the Children retrofitted 58 buildings of 19 schools in the study area. On-site inspections of the buildings were carried out to assess the strength parameters. The inspections revealed that some of the buildings had insufficient steel bars and overall cross-sections were not sufficient to meet the standards of earthquake-proof construction. Some of the buildings also suffered from poor workmanship and use of lower quality materials which caused cracks in both structural and non-structural elements, making them vulnerable to future earthquakes. Out of the 19 schools (58 buildings) surveyed, 13 schools (41 buildings) were found vulnerable and required immediate intervention. Although 6 schools (17 buildings) did not require major structural intervention, minor retrofitting and repair work was done and additional measures were taken to make them more child friendly.

Although the buildings were found vulnerable, it was not easy to decide and implement the retrofitting work in the buildings as the communities were not aware of the risks those buildings posed in future earthquakes. Save the Children decided to confront these challenges with the retrofitting process as the tool to demonstrate the risks resulting from poor design and construction and to raise awareness about disaster risks and measures for disaster risk reduction. In addition to risk reduction measures, the retrofitting work also involved incorporation of child friendly features in the schools. The need for child friendly and safer school

Table 1. Summary of damage in Aceh Province, Indonesia, following the December 2004 earthquake and tsunami

\begin{tabular}{|c|c|c|c|}
\hline & Damaged Buildings and Infrastructure & Extent of Damage & Percentage \\
\hline \multirow[t]{2}{*}{ Housing and settlement } & Settlement areas & 173,673 ha & 34.8 \\
\hline & Houses & 116,880 units & 57 \\
\hline \multirow[t]{4}{*}{ Public buildings } & Health facilities & 693 units & 66 \\
\hline & School buildings & 1,662 units & 46 \\
\hline & Government buildings & 1,412 units & 70.6 \\
\hline & Markets/Kiosks & 1,416 units & 75 \\
\hline \multirow[t]{3}{*}{ Infrastructure } & Arterial roads & $654 \mathrm{~km}$ & 27.5 \\
\hline & Provincial highways & $603 \mathrm{~km}$ & 38 \\
\hline & Bridges & 2,267 units & 66.5 \\
\hline
\end{tabular}


construction is underscored by many agencies and is recommended in guidance notes on safer school construction developed by the Global Facility for Disaster Risk Reduction (GFDRR 2009). The general process and approach of retrofitting for safer and child friendly schools adopted by Save the Children is documented in a manual developed by Save the Children after the retrofitting work (Shrestha et al. 2009).

The retrofitting project was designed with clearly assigned roles and responsibilities and a stepwise approach to ensure that communities had the opportunity to observe the complete process and realize the rational for retrofitting. The goal, ultimately, was to raise awareness about disaster risks and measures for disaster risk reduction and to build the capacity of the local communities for constructing safer and child friendly school buildings.

Communities were involved as observers in the overall retrofitting process from vulnerability assessment to design and construction. The vulnerability of the school buildings, the reasons for the need to make school buildings safer, and the proposed intervention to make the buildings safer were discussed with community members, teachers, school management personnel, and students from the initial stage of the project. They were also encouraged to observe the retrofitting process and the engineers on site explained the technical details and complete process to the communities.

Retrofitting is not as simple as new construction and requires special attention as each structure may require a unique approach. Retrofitting involves working on an existing structure without affecting the overall integrity of the existing elements. Keeping the technological challenges in mind and also with the intention of involving the communities, teachers, and students in the process, Save the Children decided not to hire a contractor but to work with a team of hired engineers and skilled laborers directly. Five engineers and 30 skilled laborers from the area were recruited and the retrofitting started in two schools as a demonstration project, which provided on-the-job training for the team.

After the completion of the first two buildings, the trained engineers were divided among five sites, with six trained laborers for each site, until the retrofitting of the 58 buildings was completed. In the process more engineers and laborers were trained. In total, seven engineers and about 200 skilled laborers were trained to carry out retrofitting work in buildings. Community members were also involved at different stages of the process and had the opportunity to observe the quality control measures, the cause and effect of substandard construction work, the effect of poor materials, and the technological challenges that required professional input and supervision to ensure safer construction.

\section{Survey Method}

The survey was conducted at the end of the reconstruction program, from February to March 2009, after the retrofitting work of houses, schools, and health facilities was completed and the facilities were occupied. The objective of the research was to assess the impact of retrofitting work on raising awareness and transferring know-how of construction work that makes buildings safer in the communities. To achieve this objective, we collected data on the community impact of the retrofitting of school buildings carried out by Save the Children in the four districts of the study area. A questionnaire survey was carried out among the persons who were directly involved in the retrofitting process of the 19 school facilities and who were from within the community. The survey excluded persons who were involved in the process but worked on behalf of the implementing agencies. The survey also excluded persons who were directly involved in the construction such as masons and laborers. The respondents were community members, teachers, and school management personnel who were encouraged to observe the retrofitting process and to whom the details were explained. Although their degree of participation was not recorded during the survey, the respondents participated in the events regularly. Involvement in the construction committee and participation in meetings were considered as participation and observation.

Data were collected by a team of community mobilizers and technical staff, well versed in the local language, through interviews with individual household members, teachers, and community leaders involved in the retrofitting process. The team was trained before conducting the survey to create a standard protocol and provide orientation in explaining each question to the interviewees. The survey team filled out the responses in the questionnaire during the interviews.

\section{Results and Discussion}

People from different backgrounds participated in the retrofitting process of the school buildings, from planning to execution stages. Among the participants, a total number of 104 people were interviewed. The survey results were tabulated and analyzed to investigate the impact of the projects on transferring know-how of retrofitting and raising awareness of disaster risks and measures for disaster risk reduction.

\subsection{Background and Damage Information of the Respondents}

Of the respondents, 64.8 percent are female, 37 percent are aged 30 and below, and only about 12 percent are aged 51 or above. Age distribution of the respondents is shown in Figure 2. The high percentage of people below age 40 (more than $65 \%$ ) is due to the interest of younger people from the community in the process and the involvement of younger teachers.

The majority of the respondents have either school education or above ( $83 \%$ ) and only five percent are illiterate. Fortyfour percent of the respondents are salary men, 30 percent are self-employed, and 10 percent are unemployed (Figure 3), while 16 percent did not disclose their occupation. 


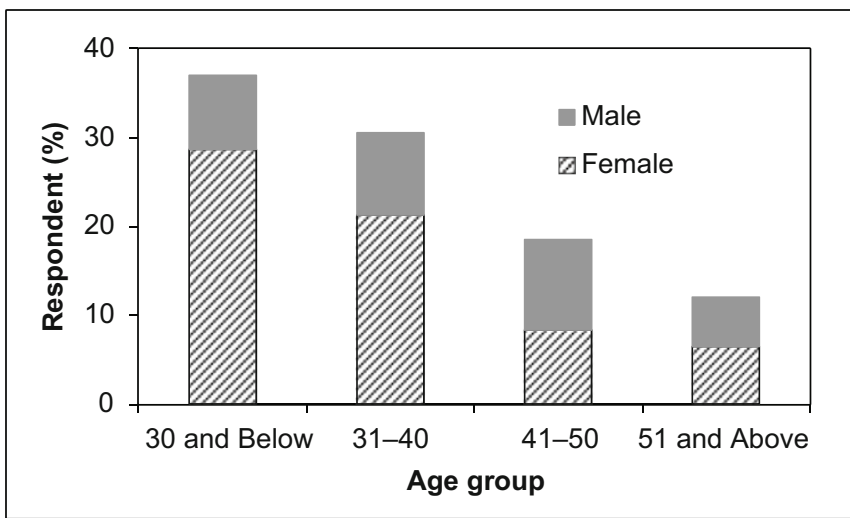

Figure 2. Age distribution of the respondents in Aceh Province, Indonesia

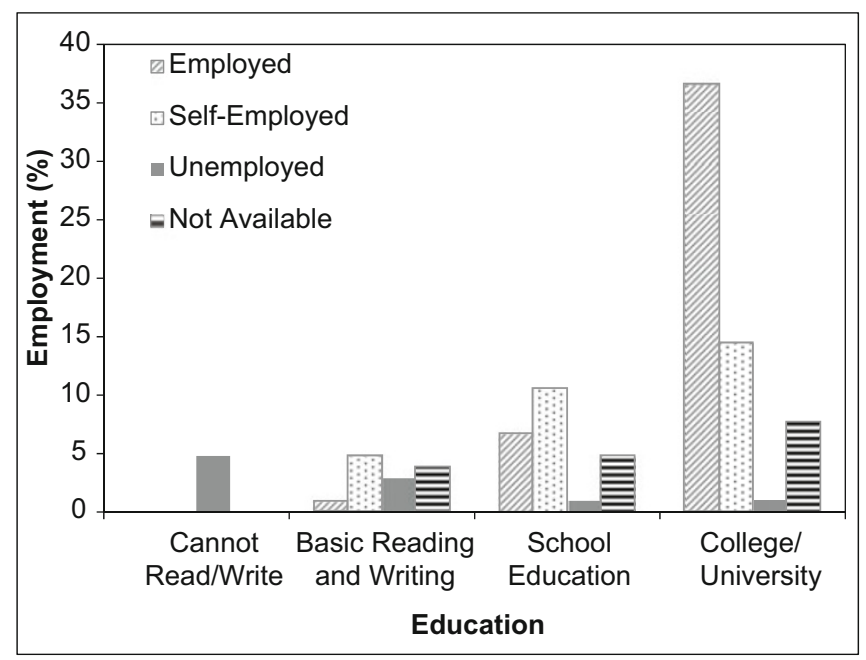

Figure 3. Education and employment of the respondents in Aceh Province, Indonesia

The respondents, all from the tsunami hit area, were affected by the disaster with different severity. To assess the impact of the disaster on each respondent, they were asked about the damage to their houses and casualties in their families and social environment (Figure 4). The houses of the majority of the respondents were either severely damaged $(39 \%)$ or partially damaged $(33 \%)$, but 28 percent experienced no adverse impact to their houses.

To assess the severity of the tsunami impact at personal level, the respondents were asked about damage to their houses and death in their family (see Figure 4). Among the respondents, 70 percent reported that either a household member $(20 \%)$ or a member in their extended family $(50 \%)$ was killed. Another 18 percent said someone they knew had died from the disaster.

Among the respondents whose houses were severely damaged, 12 percent of the total 104 respondents had someone in their household killed, 20 percent had someone in their extended family killed, 13 percent had neighbors or someone they knew who died in the disaster, and four percent were

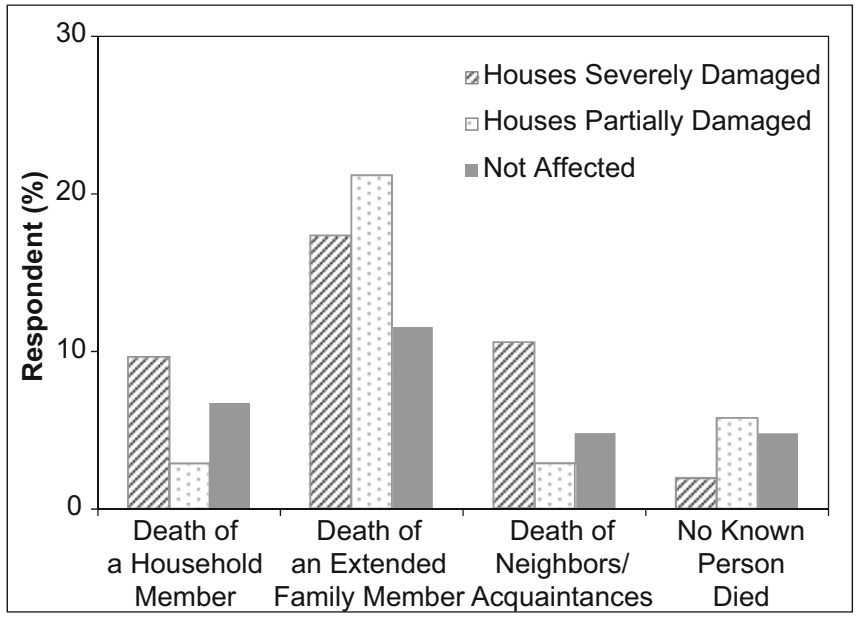

Figure 4. Impact of the 2004 tsunami disaster in Aceh Province on the respondents in terms of damage to their houses and casualties in their families and social environment

lucky to have no one they knew die in the disaster. The extent of the impact from the tsunami is reflected in the fact that the majority of the respondents experienced the death of someone close. This may explain why those who were directly impacted by the disaster were more motivated to participate in the process of retrofitting.

\subsection{Impact of Retrofitting Work}

One of the questions the respondents were asked was about the effectiveness of the retrofitting work as a means of transferring know-how to the communities. Twenty-eight percent of respondents felt that their involvement in retrofitting was effective in transferring the know-how to the communities and another 14 percent felt that it had a positive but marginal impact (Figure 5). Twenty-nine percent of the respondents felt that involvement in the retrofitting work made no contribution to the transfer of knowledge in the communities and an equal percentage of people were reluctant to answer.

Of the 39 percent of the respondents whose houses were severely damaged, 13 percent agree that the retrofitting work definitely transfers the knowledge to the community, 8 percent agree that the retrofitting work has marginal impact on knowledge transfer, and 11 percent feel that it has no impact at all. Interestingly, people whose houses were severely or partially damaged by the disaster were fairly evenly divided in their opinions about the effectiveness of retrofitting in transferring know-how The people whose houses were not affected by the disaster had a feeling that the process was not effective as a way to transfer know-how (see Figure 5).

The results show that involving people in the communities in retrofitting work to transfer know-how to the communities was not very effective. This may be because, even after being completely involved in the process, the respondents did not feel confident about their knowledge of retrofitting in a manner that would allow them to execute the appropriate 


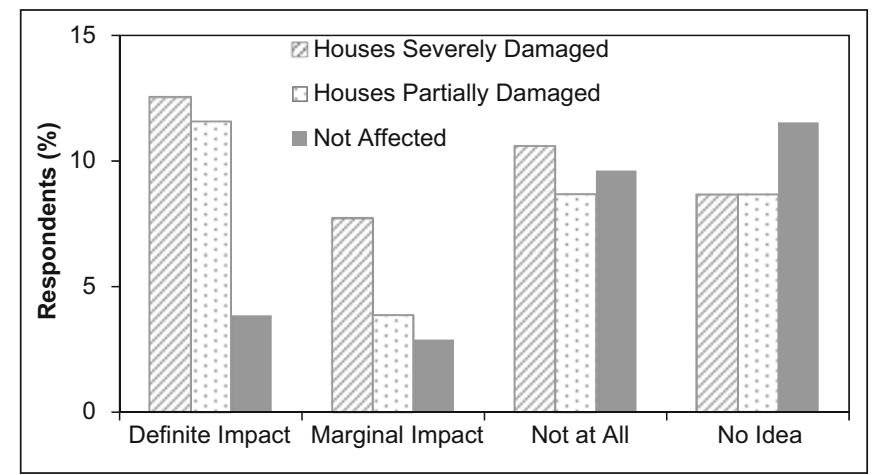

Figure 5. Perception of the respondents in Aceh Province, Indonesia of the impact of retrofitting on knowledge transfer, based on the level of damage to their houses

measures independently later. Retrofitting work is a technically challenging process and because of the lack of traditional knowledge in this kind of work, it is understandable that the communities were not confident about carrying out the work by themselves independently.

The impact of retrofitting work on knowledge transfer was marginal and had mixed responses. However, the respondents felt that the retrofitting work is more effective in raising community awareness of disaster risks and risk reduction measures. Fifty-five percent of respondents felt that retrofitting work was effective in raising awareness, with 42 percent saying the work had definite impact and 20 percent said that it had no impact at all, while 25 percent of the respondents offered no opinion. The results indicate that although communities' participation is not a panacea for all disaster management problems as pointed out by Allen (2006), their participation helps to raise awareness. Awareness is one of the key factors that contribute to making decisions to implement disaster risk reduction measures (Subedi 2010).

The view of different age groups on the impact of retrofitting work on awareness raising and knowledge transfer is shown in Figure 6a and Figure 6b. In the case of awareness raising (Figure 6a), the respondents in the age group 30 and below are fairly evenly divided between the responses of definite impact and no impact. Larger shares of respondents from other age groups felt that the retrofitting work has had definite impact on awareness raising. Larger numbers of respondents from the two age groups below 40 (more than $65 \%$ of under 40 -year olds) were either unsure or felt that the retrofitting work has had no impact at all on the transfer of know-how to the communities. A higher percentage of respondents (59\%) from the age groups 40 and above felt that it has either definite impact or marginal impact on the transfer of know-how to the communities (Figure 6b). The results indicate that effectiveness of participation is different among different age groups with lower effectiveness among younger participants.

The results also show that respondents' view of the impact of retrofitting work varies according to the level of education
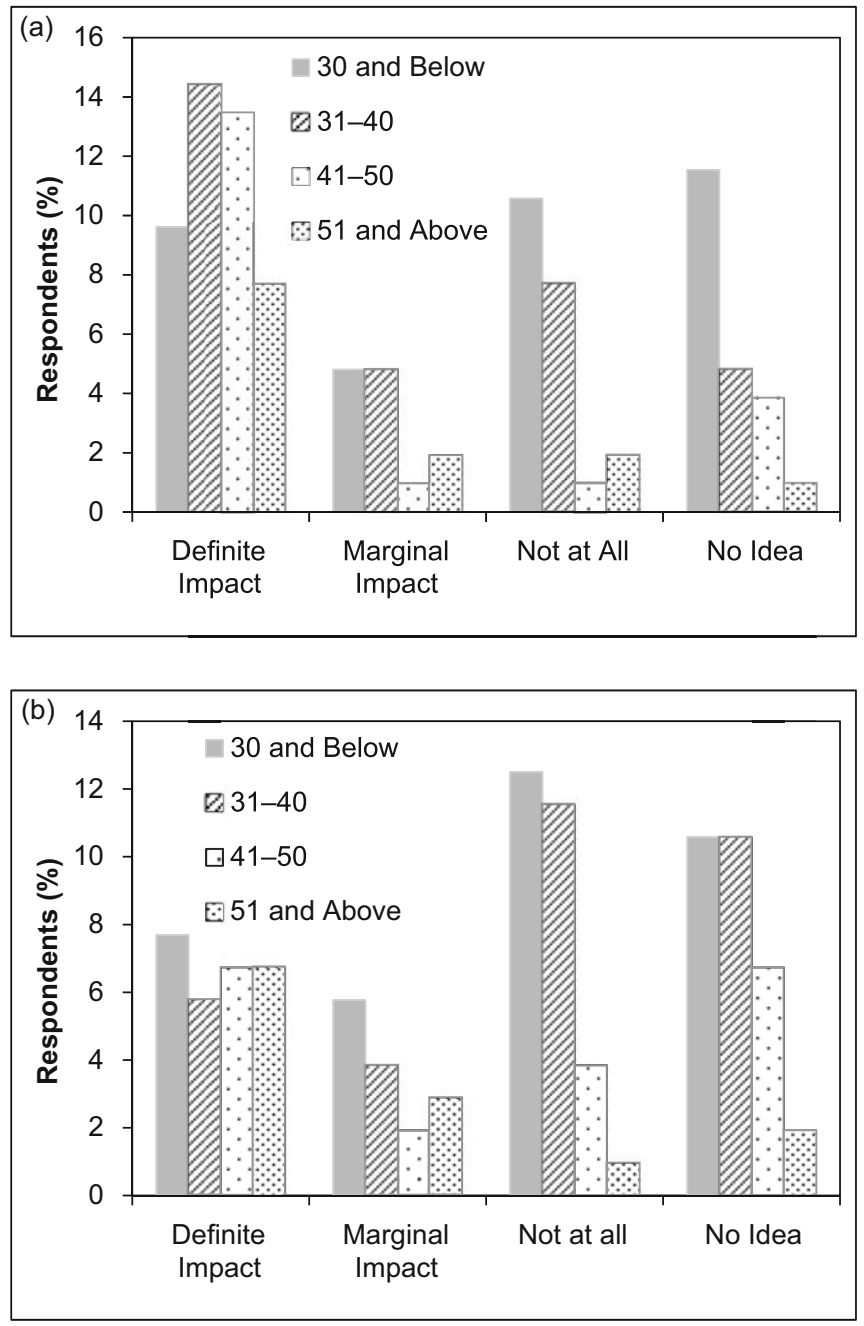

Figure 6. Impact of retrofitting work on disaster risk and risk reduction measure awareness raising in communities of Aceh Province, Indonesia (a) and on transfer of retrofitting know-how in the communities (b)

(Figure 7). All respondents who could not read and write (5\%) responded that the retrofitting work had definitive impact on awareness raising. A larger share of the respondents with basic reading and writing capacity also felt that the retrofitting work had a definite impact (8\%) compared to three percent who said that it had no impact on awareness raising. The respondents with a college level education were divided in their opinions about the effectiveness of retrofitting on awareness raising.

The impact of retrofitting work on raising awareness of the respondents in relation to the death of someone close in the tsunami disaster is shown in Figure 8. Respondents who had someone close to them killed perceive higher impact on awareness raising from the retrofitting work. The reason for this might be their increased eagerness to learn as they feel the threat from earthquake hazard to be more immediate.

Karanci, Aksit, and Dirik (2005) also argue that exposure to disaster awareness programs increases threat perceptions 


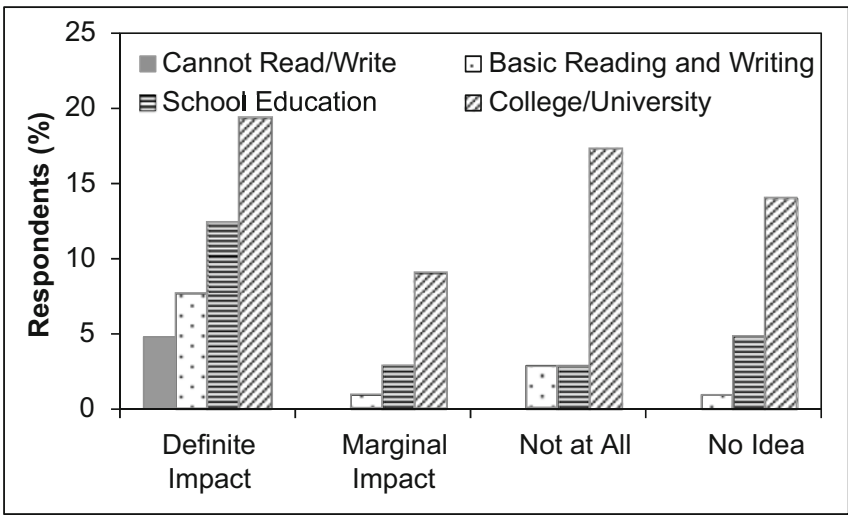

Figure 7. Impact of retrofitting work in Aceh Province, Indonesia on disaster risk and risk reduction measure awareness raising based on level of education

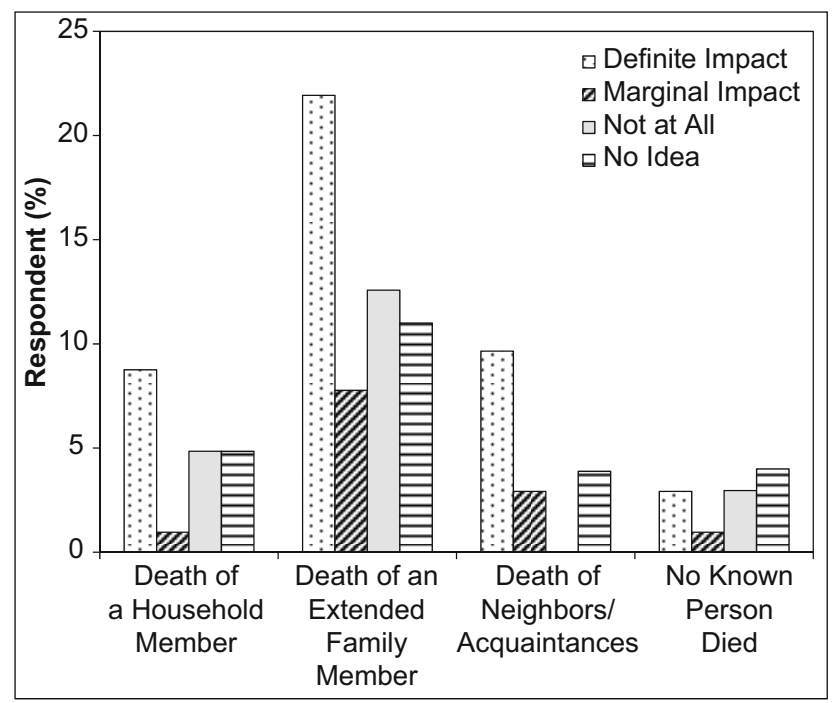

Figure 8. Impact of retrofitting in Aceh Province, Indonesia on disaster risk and risk reduction measure awareness raising in relation to the death of a person close to the respondent

and increases worry about future disasters. The increased threat perception can be instrumental in actions to reduce disaster risks. However, participation in disaster risk reduction activities is not equally effective in raising awareness of disaster risks and measures for disaster risk reductions among different age groups and people from different education backgrounds. In addition to participation, other approaches toward awareness raising such as inclusion in formal education, trainings, and regular drills should also be adopted.

\section{Conclusion}

The Hyogo Framework for Action 2005-2015 underscores the fact that community participation and transfer of knowhow to communities are two major cross-cutting issues in building resilience of communities and nations to disasters. A survey of respondents who participated in the retrofitting work of school facilities in Aceh Province, Indonesia was carried out to assess people's perception on the impact of their participation on awareness raising and knowledge transfer. The survey revealed that there is a positive impact on people who participated in the retrofitting work in raising their awareness of disaster risks and measures for disaster risk reduction. A large number of respondents felt that the retrofitting work has had definite impact on raising their awareness. Increased level of awareness can be instrumental to making decisions in implementing risk reduction measures.

However, the survey also showed that people perceive that participation of communities in the retrofitting works did not help to transfer technology of retrofitting to the communities. This may be because retrofitting is a new concept and requires experience and skill. Although construction is a regular activity in the communities and they have traditional knowledge in it, it is confined to new construction and repair and maintenance of buildings. Due to lack of traditional knowledge in retrofitting, members of the local communities did not feel confident about carrying out retrofitting activities independently later on.

Community participation has long been recognized as an effective way for sustainability of projects. Technology transfer for activities such as retrofitting that are relatively new to the communities, however, cannot be achieved through community participation alone. Packaging participation in mitigation projects along with other approaches such as training and regular drills can be effective ways to increase awareness and knowledge transfer among all cross-sections of people.

\section{References}

Allen, K. M. 2006. Community-Based Disaster Preparedness and Climate Adaptation: Local Capacity-Building in the Philippines. Disasters 30 (1): 81-101.

Davidson, C. H., C. Johnson, G. Lizarralde, N. Dikmen, and A. Sliwinski. 2007. Truths and Myths about Community Participation in PostDisaster Housing Projects. Habitat International 31 (1): 100-115.

GFDRR (Global Facility for Disaster Risk Reduction). 2009. Guidance Notes on Safer School Construction. http://gfdrr.org/docs/Guidance_ Notes_Safe_Schools.pdf.

IOM (International Organization for Migration). 2005. Post Disaster Damage Assessment in Nanggroe Aceh Darussalam. http://www.iom. or.id/reports.jsp.

Karanci, N. A., and B. Aksit. 2000. Building Disaster-Resistant Communities: Lessons Learned from Past Earthquakes in Turkey and Suggestions for the Future. International Journal of Mass Emergencies and Disasters 18 (3): 403-416.

Karanci, A. N., B. Aksit, and G. Dirik. 2005. Impact of a Community Disaster Awareness Training Program in Turkey: Does It Influence Hazard-Related Cognitions and Preparedness Behaviors? Social Behavior and Personality 33 (3): 243-258.

Kennedy, J., J. Ashmore, E. Babister, and I. Kelman. 2008. The Meaning of "Build Back Better": Evidence from Post-Tsunami Aceh and Sri Lanka. Journal of Contingencies and Crisis Management 16 (1): $24-36$. 
Oxfam International. 2005. A Place to Stay, A Place to Live: Challenges in Providing Shelter in India, Indonesia, and Sri Lanka after the tsunami. Oxfam Briefing Note. Oxford: Oxfam International.

Pearce, L. 2003. Disaster Management and Community Planning, and Public Participation: How to Achieve Sustainable Hazard Mitigation. Natural Hazards 28 (2-3): 211-228.

Shrestha, H. D., K. S. Pribadi, D. Kusumastuti, and E. Lim. 2009. Manual on Retrofitting of Existing Vulnerable School Buildings Assessment to Retrofitting. http://www.preventionweb.net/files/ 17195_17195book2manualonretrofittingparti.pdf.

Shrestha, H. D., Y. Yatabe, N. P. Bhandary, and J. Subedi. 2012. Vulnerability Assessment and Retrofitting of Existing School Buildings: A
Case Study of Aceh. International Journal of Disaster Resilience in the Built Environment 3 (1): 52-65.

Subedi, J. 2010. Disaster Informatics: Information Management as a Tool for Effective Disaster Risk Reduction. In: Advanced ICTs for Disaster Management and Threat Detection: Collaborative and Distributed Frameworks, edited by E. Asimakopoulou and N. Bessis, 80-94. Hershey, PA: IGI Global.

UNISDR (United Nations International Strategy for Disaster Risk Reduction). 2005. Hyogo Framework for Action 2005-2015: Building Resilience of Nations and Communities to Disasters. http://www. preventionweb.net/files/1037_hyogoframeworkforactionenglish.pdf.

Open Access This article is distributed under the terms of the Creative Commons Attribution License which permits any use, distribution, and reproduction in any medium, provided the original author(s) and source are credited. 